\title{
EDUCAÇÃO DE PESSOAS SURDAS EM TEMPOS DE PANDEMIA: LINGUAGEM E RELAÇÕES DE PODER
}

Jéssika Figueredo Alves ${ }^{\mathrm{i}}$

Jacqueline de Souza Gomes ${ }^{\text {ii }}$

\begin{abstract}
Resumo: Este artigo analisa os efeitos da pandemia de COVID-19 na educação de pessoas surdas no município de Santo Antônio de Pádua-RJ, considerando os enfrentamentos que subsistiam antes mesmo da suspensão das aulas presenciais, tais como o ouvintismo, a desvalorização da língua de sinais e o preconceito linguístico que reprova a expressão escrita e oral da pessoa surda. Através de estudo de caso, apresentamos as reformulações e tentativas adotadas pelas escolas públicas do município para dar sequência às atividades escolares, discutindo a realidade de alunos(as) surdos(as) matriculados(as) na rede, a atuação de intérpretes e os aspectos linguísticos a serem considerados no ensino virtual.
\end{abstract}

Palavras-chave: Educação de surdos; Intérprete; Linguagem; Pandemia; Democracia.

\section{EDUCATION OF DEAF PEOPLE IN TIMES OF PANDEMIC: LANGUAGE AND POWER RELATIONS}

\begin{abstract}
This article analyzes the effects of the COVID-19 pandemic on the education of deaf people in the municipality of Santo Antônio de Padua-RJ, considering the confrontations that persisted even before the suspension of face-to-face classes, such as ouvintism, the devaluation of sign language and linguistic prejudice that disapproves of the written and oral expression of the deaf person. Through a case study, we present the reformulations and attempts adopted by the public schools of the municipality to continue the school activities, discussing the reality of deaf students enrolled in the network, the performance of interpreters and the linguistic aspects to be considered in virtual education.
\end{abstract}

Key words: Deaf education; Interpreter; Language; Pandemic; Democracy.

\section{Introdução}

Saio da janela, sento-me numa cadeira. Em que hei de pensar? Que sei eu do que serei, eu que não sei o que sou? Ser o que penso? Mas penso tanta coisa! E há tantos que pensam ser a mesma coisa que não pode haver tantos! Fernando Pessoa - Tabacaria

Certezas dão-nos uma ilusão de segurança. Contudo, talvez, de fato, uma única delas possa se justificar, qual seja, a que reconhece que vivemos à mercê da inconstância, de fortuitos acontecimentos que nos afetam, nos abalroam e nos paralisam ao mesmo tempo em que nos questionam e nos pedem respostas rápidas. Inconstâncias que, inclusive, nos convidam a novas 
rotinas, como a que vivemos nestes tempos de pandemia de Covid-19. Fomos obrigados a sair da janela de segurança e de controle que julgávamos ter. Escaparam-nos as certezas sobre o mundo e nos deparamos com a urgente necessidade de repensarmos nossas prioridades e valores. Tem sido um momento de ressignificação do que somos e do que fazemos. Momento de desconstrução de nós mesmos e dos sentidos de nossa existência.

Esta urgente necessidade de reavaliação do pensamento conduz a Educação, especialmente a Educação Básica, a reformulações. Acostumamos-nos com uma organização, com uma logística em torno das escolas, fruto de sua estrutura física e que, hoje, não podemos nos referenciar. Como, então, estabelecer um ensino democrático sem utilizarmos do espaço físico das nossas instituições escolares? Alternativas variam de acordo com estados, municípios, escolas, turmas, até chegarmos nos(as) alunos(as). Inúmeras variáveis atravessam o acesso à aprendizagem, tornando difícil mapeá-las de forma ampla. Frente a isto, para entendermos os efeitos de forma global, partimos do local, do lugar que estamos e, assim, nosso objetivo foi, a partir da observação sobre como tem se estabelecido a educação de surdos no município de Santo Antônio de Pádua, cidade do Noroeste do estado do Rio de Janeiro, durante este tempo de isolamento, compreender alguns dos percalços que se apresentam para a materialização da educação de pessoas surdas e refletimos sobre os impactos psicossociais do reconhecimento de uma língua. Inquietamo-nos sobre quais estratégias e tentativas estão sendo adotadas, sobre quais as dificuldades encontradas (considerando, inclusive, as que já existiam) e quais as alternativas possíveis.

O artigo está estruturado em 3 (três) seções. Começamos a investigação a partir da exposição de estudo de caso que foca na educação de pessoas surdas no município de Santo Antônio de Pádua/RJ. A educação de pessoas surdas neste município, no pré-pandemia, como em tantos outros municípios, já enfrentava inúmeros desafios, dentre eles o preconceito linguístico, o estigma da deficiência/ausência e o de não render-se às pressões ouvintistas (que consideram a pessoa surda uma minoria que precisa se adaptar às "normas" hegemônicas). Reportando-nos ao poema Tabacaria, de Fernando Pessoa, "há tantos que pensam ser a mesma coisa que não pode haver tantos!”. Reforce-se, com Skliar (2006, p. 23), que “as diferenças não podem ser apresentadas nem descritas em termos de melhor e/ou pior, bem e/ou mal, superior e/ou inferior, positivas e/ou negativas, maioria e/ou minoria etc. São, simplesmente - porém não simplificadamente - diferenças". É justamente essa diferenciação que leva o julgado “diferente" a ser uma espécie de "problema social”, como o é a pessoa surda (que é, ainda, um tal "problema de natureza linguística"). Na seção seguinte, trazemos esclarecimentos sobre a atuação do intérprete de Libras e pontuamos aspectos linguísticos que precisam ser 
considerados diante às novas modalidades de ensino adotadas. Por fim, refletimos sobre o preconceito lingüístico que permeia a ausência de valoração à língua utilizada pela pessoa surda, através de um diálogo com a literatura.

\section{Ponto de Partida: estudo de caso sobre a educação de pessoas surdas em tempos de pandemia}

Em Santo Antônio de Pádua, município do Noroeste Fluminense do estado do Rio de Janeiro, no dia 13 de março de 2020 foi publicado o Decreto Municipal no 027 que "dispõe sobre medidas temporárias de prevenção ao contágio e de enfrentamento da propagação decorrente do novo coronavírus (COVID-19), e dá outras providências”. Dentre as medidas desta norma está a suspensão das aulas presenciais. Como em tantos outros países, a medida foi necessária no Brasil, em vários municípios, para o enfrentamento da pandemia e a continuidade do ensino tornou-se um desafio para as escolas e famílias, especialmente devido às já recorrentes dificuldades de acesso democrático aos conteúdos e ao cumprimento satisfatório do calendário regular.

As atividades escolares ficaram totalmente paralisadas durante quase um mês, enquanto os profissionais da educação e gestores definiam alternativas para as diversas demandas insurgentes. A Secretaria Municipal de Educação desenvolveu e disponibilizou um site com atividades preparadas pelos professores e professoras da rede; porém, em vista da quantidade de acesso e downloads, foi verificado que não estava sendo muito eficaz. Com isso, cada escola passou a tomar iniciativas próprias, até que, no dia 27 de abril de 2020, a prefeitura publicou um novo Decreto, de $n^{\circ}$ 051, antecipando as férias escolares, o que permitiria novas reuniões para estudo de possibilidades. Decorrido os 15 dias, alguns funcionários retornaram à escola, porém em escala, para organizar os materiais recebidos, entregar os livros didáticos na casa das crianças, imprimir, tirar xerox e levar atividades para os alunos que moram na zona rural e não possuem acesso à internet. Foram formados grupos de WhatsApp para as turmas que ainda não tinham, de forma a favorecer o contato com os alunos, mesmo que nem todos fossem inseridos devido à questão da internet, como já mencionada.

E como está acontecendo a educação para os alunos surdos? Atualmente a rede possui dois alunos surdos matriculados, uma menina de 11 anos que está no $5^{\circ}$ ano e um menino de 9 anos que está no $4^{\circ}$ ano. A menina mora na zona rural, não tem acesso à internet e as atividades escolares estão sendo entregues em sua casa. A professora, em parceria com a intérprete, tem selecionado atividades de acordo com as necessidades e possibilidades da aluna, pois muitos 
conteúdos não são de conhecimento da família e apresentá-los poderia dificultar o acompanhamento da aluna em casa. A aluna tem recorrido, com frequência, a uma colega que mora próximo a sua casa para ajudá-la na realização das tarefas. Já o menino mora no centro de Santo Antônio de Pádua, tem acesso à internet, o que facilita a oferta de recursos pedagógicos variados. Contudo, não consegue acompanhar os grupos de WhatsApp por não conhecer muito do português escrito e por áudios e vídeos não serem acessíveis. Com isso, a intérprete tem realizado a função de passar os conteúdos propostos por chamada de vídeo, através da Língua Brasileira de Sinais.

São duas realidades bem distintas que nos levam a pensar sobre os desafios enfrentados pelos profissionais intérpretes. No primeiro caso, o de não ter o campo visual, o contato com a aluna, o que limita o seu trabalho, e, no segundo caso, de ser a referência para o aluno, o que pode levá-lo a projetar no intérprete a função de seu professor. A semelhança entre os dois casos é o fato de estarem distante da interação com turma. Aulas por plataformas virtuais não foram adotadas por razões específicas de acesso por parte dos alunos e, mesmo se fossem, os alunos surdos possivelmente esbarrariam em dificuldades quanto à acessibilidade. A imagem, a articulação da fala, muitas vezes não é nítida, o que é um complicador para surdos oralizados e até mesmo para os que sinalizam. A conexão com a internet pode falhar. Há inúmeros desafios. Vivemos um período de reinvenção, de busca por estratégias para minimizar os efeitos do distanciamento social. É fundamental zelar por relações de afeto capazes de manter os vínculos com os alunos de alguma forma.

Em aulas presenciais já havia lutas, preconceito, o menosprezo por serem 1(um) em 1 (uma) escola, o querer delegar ao intérprete a responsabilidade de ensinar o surdo, de confundir as atribuições de sua função com a de um mediador escolar, dentre outros pontos que, não só continuam em tempos de pandemia, mas que se acentuam. Há uma desvalorização na função do intérprete, falas como "ele está ali só para aquele aluno, então o professor não precisa se preocupar”. Assim, para lidar com a realidade e com as condições desfavoráveis não como empecilhos (embora sejam), mas como características do nosso espaço-tempo de atuação, é importante um olhar somativo e não comparativo sobre nossos alunos. É um processo.

\section{Atuação do Intérprete de Libras no Ensino Virtual: alguns esclarecimentos}

Um mesmo lugar, uma mesma função. Esta é a lógica utilizada por muitos, não só por educadores, que resulta na inserção ilusória do Intérprete de Libras na gama de profissionais de apoio escolar, comumente chamados de mediadores escolares. Há uma notável diferença entre 
os papéis desempenhados por estes profissionais e que precisa ser esclarecida para que os efeitos dessa confusão não respinguem na atuação dos intérpretes em forma de cobranças descabidas e desconfortáveis. Baseando-nos na Lei Brasileira de Inclusão da Pessoa com Deficiência, $n^{\circ} 13.146$ de 6 de julho de 2015, entendemos por:

XIII - profissional de apoio escolar: pessoa que exerce atividades de alimentação, higiene e locomoção do estudante com deficiência e atua em todas as atividades escolares nas quais se fizer necessária, em todos os níveis e modalidades de ensino, em instituições públicas e privadas, excluídas as técnicas ou os procedimentos identificados com profissões legalmente estabelecidas.

Diferentemente do profissional de apoio escolar, a profissão de Tradutor e Intérprete da Língua Brasileira de Sinais - LIBRAS é legalmente reconhecida, regulamentada pela Lei ${ }^{\circ}$ 12.319 , de $1^{\circ}$ de setembro de 2010 , que dispõe em seu art. $2^{\circ}$ que "O tradutor e intérprete terá competência para realizar interpretação das 2 (duas) línguas de maneira simultânea ou consecutiva e proficiência em tradução e interpretação da Libras e da Língua Portuguesa". Para tanto, necessita de formação específica, técnica e ter uma postura adequada, como determinado na referida lei e no Código de Ética da profissão.

O intérprete deve mediar a comunicação, conforme já mencionado, e trabalhar em parceria com o docente no sentido de orientá-lo em questões relacionadas à surdez para favorecer sua relação com o aluno, sempre com respeito e honestidade. Considerando o estudo de caso realizado no Município de Santo Antônio de Pádua, em que as aulas estão acontecendo em grupos de whatsapp, por ser um aplicativo mais comum, o Intérprete deve encontrar formas de viabilizar a comunicação, pois mensagens de texto e áudios são, por vezes, insuficientes para uma boa compreensão. Uma opção é o docente combinar com o aluno/familiares um horário adequado para realizar uma videochamada, que pode ser pelo mesmo aplicativo (whatsapp), para passar o conteúdo ou esclarece-los, com a presença do intérprete.

As funções e os espaços precisam estar bem especificados, delimitados, para uma boa relação e andamento das atividades escolares. O Intérprete não deve interferir nas mensagens enviadas pelo professor, corrigir erros identificados em sua atuação, responder questionamentos de alunos sobre as atividades propostas, precisa ter fidelidade ao passar a informação que está sendo transmitida pelo docente, mesmo que não concorde com ela, ou seja, deve agir de forma imparcial, sem colocar suas impressões sobre o tema abordado. Portanto, não compete ao profissional intérprete a elaboração de atividades ou adaptações para alunos(as) surdos(as), como é esperado e cobrado por muitos educadores, orientadores pedagógicos e diretores. Não se trata de "má vontade", de "não querer ajudar", trata-se do que está contido no art. $3^{\circ}$ do 
Código de Ética da profissão: "Ele deve lembrar dos limites de sua função e não ir além de sua responsabilidade" (QUADROS, 2007, p. 31). O Intérprete não é um segundo professor e práticas como as citadas reforçam a confusão sobre quais atribuições competem ao Intérprete de Libras, que, ao deixar-se levar pelas cobranças externas, torna ainda mais distante a expectativa de mudar esta realidade. Ainda sobre a falta de esclarecimento sobre as atribuições de cada profissional, vale dizer que:

A confusão de papéis existente em sala de aula gera confusão também em outras esferas de relação, como as que envolvem escola-família. Muitos pais e/ou responsáveis de estudantes surdos buscam informações sobre o desenvolvimento dos filhos surdos diretamente com os intérpretes, evidenciando uma total dependência desse profissional em todos os aspectos que tratam dos surdos (DORDIAT, 2012, p. 404).

Portanto, é importante que o intérprete esteja atento à sua própria atuação em relação ao aluno. Conforme o inciso II do art. $6^{\circ}$ da Lei $n^{\circ} 12.319$, de $1^{\circ}$ de setembro de 2010 , que dispõe sobre suas atribuições, compete a ele "interpretar, em Língua Brasileira de Sinais - Língua Portuguesa, as atividades didático-pedagógicas e culturais desenvolvidas nas instituições de ensino nos níveis fundamental, médio e superior, de forma a viabilizar o acesso aos conteúdos curriculares". Desta forma, o profissional deve favorecer o acesso aos conteúdos e não realizar as tarefas para o aluno, dar respostas, pois, desta forma, estará impedindo seu aprendizado e o desenvolvimento de sua autonomia, além de ir contra ao determinado no código de ética.

É preciso respeitar o tempo do aluno, deixar que realize as tarefas com qualidade para que tenham significado. Talvez este seja um ponto positivo em meio a inúmeros negativos trazidos pela pandemia, em relação ao caso do Município de Santo Antônio de Pádua: a flexibilidade no tempo para a realização das tarefas, pois, presencialmente, existe a preocupação dos docentes pelo cumprimento de seu plano de aula, que os levam a controlar o tempo estipulado para cada atividade. Assim, aqueles alunos que necessitam de um tempo maior para realizá-las, simplesmente copiam as respostas e seguem para a próxima atividade, eximidos da oportunidade de viver a diferença e respeitarem-se na diversidade.

\section{Aspectos linguísticos em evidência}

A educação de pessoas surdas em escolas regulares incute na inclusão da diferença linguística, que, com a adesão das aulas virtuais, foi dificultada por tratar-se de uma língua gestual-visual, considerando os desafios também enfrentados pelos não-usuários da Libras que 
necessitam do campo visual para realizarem a leitura labial. O ensino por aplicativos de vídeo, dentre as possibilidades, é o que mais se aproxima da dinâmica da sala de aula devido à interação em tempo real e por permitir o contato visual, que é essencial para a atuação do intérprete e para o entendimento do(a) aluno(a) surdo(a) quanto ao que está sendo discutido, pois, conforme Bakhtin:

A expressão facial e os gestos têm, com frequência, uma importância semelhança à da entonação, isto é, determinadas imagens modificam os sentidos das palavras. A mímica (expressão facial) e os gestos, sendo companheiros constantes de qualquer reação do homem, são meios comunicativos constantes e poderosos (BAKHTIN, [1929] 2017, p. 41-42).

É importante que o docente oriente os alunos a não fecharem a câmera, como é comum acontecer em aulas online, para que suas expressões, reações e movimentos sejam visíveis. Aplicativos bastante utilizados para essa finalidade são o Google Meet, Jitsi Meet e Zoom, embora apresentem complicadores que variam de acordo com a conexão da internet, a resolução da câmera dos aparelhos eletrônicos, dentre outras questões que precisam ser colocadas em pauta com a escola e a família com o intuito de alcançar melhores resultados. $\mathrm{O}$ aplicativo whatsapp, utilizado no município de Santo Antônio de Pádua, permite a formação de grupos, o envio de documentos, imagens, áudios, mensagens de texto e vídeo chamadas com número restrito de até 8 participantes. No entanto, o recurso da chamada de vídeo não está sendo utilizado devido ao limite de pessoas e, também, por grande parte das crianças utilizarem o celular dos pais, e muitos também precisam usar por questões de trabalho/estudo. Se antes o celular já acompanhava grande parte da população por facilitar o acesso à serviços e à comunicação, no atual cenário tornou-se ainda mais indispensável.

$\mathrm{O}$ caso da menina de 11 anos ainda se esbarra na falta de acesso à internet, que a exime do contato visual. Por mais que as atividades estejam sendo entregues, é necessário uma orientação adequada para que possa compreender o que está sendo solicitado, pois sempre há algo novo, alguma palavra que precisa ser contextualizada ou "mostrada", já que seu pensamento é baseado por signos visuais. A aluna está em processo de oralização, por decisão dos pais, mas também frequentava as aulas de Libras com a presença da mãe, que aprendia junto. Com a medida do isolamento social e as dificuldades de acesso, a família tem feito o possível para que o aprendizado continue.

Neste período em que as pessoas estão passando mais tempo em suas casas, a internet é o que tem possibilitado que muitos serviços continuem ou sobrevivam, e, também, tem servido como canal de distração. E vale ressaltar que houve um aumento de entretenimento com 
interpretação em Língua Brasileira de Sinais neste período, como lives de cantores, de profissionais da saúde e da educação, que significa um cuidado e reconhecimento da diferença linguística. Portanto, é necessário esforços para que a internet se torne cada vez mais acessível, não descartando outras demandas básicas da sociedade que foram/estão sendo afetadas desde o início da pandemia.

Diante ao estranhamento e tentativas de adaptação a este novo cenário, é preciso tomar as especificidades da língua como fio condutor do processo de ensino, no entanto, é comum depararmo-nos com discussões que apontam a língua de sinais como o problema da educação, em que o(a) aluno(a) precisa transpor as barreiras linguísticas e a alternativa apontada é se aproximar ao máximo da realidade ouvinte. Talvez, um dos maiores desafios da educação seja não transformar a diferença em uma porta de desigualdades.

\section{A língua que é minha: identidade e relações de poder}

Erro de Português - Oswald de Andrade

Quando o português chegou Debaixo de uma bruta chuva

Vestiu o índio Que pena! Fosse uma manhã de sol O índio tinha despido O português.

A língua utilizada por um indivíduo representa sua forma de expressão, traduz seu pensamento e é constituída em um berço cultural, social, atravessado por relações de poder, como bem evidencia Oswald de Andrade no poema supracitado. Tendo em vista a diversidade do nosso país, é possível dizer que não estamos em um terreno monolíngue, que não há uma forma correta de falar, embora seja comum atribuirmos à norma culta padrão do português esse posto de supremacia, sendo a língua utilizada no campo acadêmico e imposta à sociedade como ideal. Não nos esquivamos de reconhecer a importância de uma língua padrão devido à circulação de material escrito, principalmente o de cunho cientifico, com o intuito de facilitar a comunicação entre as produções; porém, é preciso evitar tomá-la como parâmetro de correção da forma oral utilizada pelas pessoas, como comumente acontece. Mesmo uma língua padrão sofre alterações com o tempo, pois que não é um bloco estático.

No livro A língua de Eulália, de Marcos Bagno (2006), percebemos que, dentro do português, há inúmeras variedades e muito do que julgamos como errado perante a gramática da norma padrão tem uma justificativa segundo a análise de um conjunto que compreende 
variáveis geográficas (tempo e espaço), de gênero, de faixa etária, de nível de instrução, socioeconômicas, dentre outras. Portanto, ao nomear uma língua precisamos considerar todos esses aspectos. Ao referirmo-nos à língua de uma criança surda em processo de oralização, por exemplo, é preciso especificar que esse é o português utilizado no Brasil, no ano de 2020, por uma menina surda, um pouco oralizada, de 10 anos, que mora no interior do Noroeste Fluminense, zona rural. Como a personagem Irene menciona no livro, "é como se cada pessoa falasse uma língua só sua”. No entanto, como o Bagno coloca no início de sua obra,

A própria escola não reconhece que a norma padrão culta é apenas uma das muitas variáveis possíveis no uso do português e rejeita de forma intolerante qualquer manifestação linguística diferente, tratando muitas vezes os alunos como "deficientes linguísticos (BAGNO, 2006, p. 5-6).

A língua utilizada por um surdo oralizado pertence ao grupo das variedades do português não-padrão, faz parte da cultura brasileira, bem como a Língua Brasileira de Sinais Libras, que é uma das línguas oficiais do Brasil, regida pela Lei no 10.436 de 24 de abril de 2002 e regulamentada pelo Decreto $\mathrm{n}^{\circ} 5.626$ de 22 de dezembro de 2005, que confere ao surdo o direito de exercer sua cidadania através dessa língua, considerada a mais adequada perante sua expressão gestual-visual. Contudo, mesmo conscientes de que no Brasil não há uma só língua - e aqui destacamos, também, as utilizadas por comunidades indígenas e de imigrantes que mantiveram sua língua materna - a pessoa surda, independentemente de como se expressa, é vítima dessa "intolerância linguística", tachados como "deficientes linguísticos". A diferença entre o surdo e o ouvinte, no entanto, é que no primeiro caso a justificativa recebe o peso do estigma, da deficiência, da falta de um sentido, da aceitação do "falar errado" por não ter outro jeito.

A Libras, para muitos profissionais da educação, não é vista como língua, mas como um recurso, adaptação, que não resolve o "problema da comunicação", problema que se agravou com a medida do isolamento social, introdução de aulas virtuais, uso de máscara (que atrapalha a leitura labial e expressões). O discursos permanecem os mesmos, baseados em questionamentos do tipo "Como ela vai se comunicar com o vendedor de uma loja?", "Como vai conseguir um namorado?", "Vai trabalhar com o que?", "Ninguém sabe falar Libras por aqui!" ou algo como "Ela precisa aprender o português para se comunicar com as pessoas". Falas que reforçam o ouvintismo e tornam ainda mais distante a expectativa de uma democratização lingüística (ou seja, a possibilidade de disseminar a Língua de Sinais), pois não é só o surdo que precisa falar com os ouvintes. Também os ouvintes precisam falar com as 
pessoas surdas e, portanto, devem buscar os auxílios necessários para isso. Nas palavras de Skliar (2016), o ouvintismo

Trata-se de um conjunto de representações dos ouvintes, a partir do qual o surdo está obrigado a olhar-se e a narrar-se como se fosse ouvinte. Além disso, é nesse olhar-se, e nesse narrar-se que acontecem as percepções do ser diferente, do não ser ouvinte. [...] e o oralismo - a forma institucionalizada do ouvintismo - continuam sendo, ainda hoje, discursos hegemônicos em diferentes partes do mundo (SKLIAR, 2016, p. 15).

Dentre tantos discursos ouvintistas presenciados por uma das autoras durante sua atividade profissional, chamou atenção fato ocorrido durante uma roda de conversa sobre a temática e um dos depoimentos de professores presentes apresentou a seguinte opinião: "Acho que a pessoa surda deve aprender o português, ser oralizado, porque é a língua da maioria. Se eu for para os Estados Unidos, por exemplo, eu que tenho que saber o inglês para me comunicar e não eles saberem o português". Podemos contestar utilizando o argumento de que não se trata de um outro país, mas sobre uma língua reconhecida em seu próprio país, língua materna por lei, que não foi criada para que se sintam estrangeiros de seu próprio país, mas abraçados por uma cultura, como tantas outras existentes. Também poderiam ser usados dados para demonstrar que não é quantidade de usuários de uma língua que indica seu nível de prestígio. Como muito bem provoca Skliar (2016) em sua obra A surdez: um olhar sobre as diferenças:

Sabe-se que a língua de sinais Americana (ASL) é a terceira língua de maior uso dentro dos Estados Unidos. Mas, terá essa língua o mesmo status social, acadêmico, linguístico, que o espanhol, o chinês, o fancês? Será que aquilo que é linguisticamente muito utilizado em um determinado país também é politicamente mais reconhecido/considerado? Esses exemplos deveriam servir para demonstrar que, embora se queira estabelecer critérios quantitativos para uma política educacional, esses se tornam necessariamente qualitativos e respondem a uma hierarquia e a uma assimetria de poderes (SKLIAR, 2016, p. 23).

Todas essas questões se traduzem no investimento em que uma determinada língua recebe, não por ser mais completa, a mais adequada, mas por uma decisão hierárquica que a coloca sob o trabalho da Academia de Letras, dicionaristas e demais envolvidos na elaboração de regras e normas a serem ensinadas pelas escolas e compor o material didático. Ou seja, não diz respeito à minoria ou maioria de usuários.

Marcos Bagno (2006, p. 23) traz um exemplo que ilustra muito bem essa questão de o quantitativo não ser o ponto decisivo para uma língua ser reconhecida. Conta-se que na Nova 
Zelândia o idioma mais utilizado é o inglês devido ao processo de colonização, ou seja, relações de poder, porém, a língua maori, antes considerada um "idioma primitivo", recebeu um investimento e tornou-se uma das línguas oficiais. Atualmente há escolas, universidade, jornais, revistas e programas de televisão nesta língua. Assim como este exemplo, há tantos outros. No entanto, o que diferencia a Libras de outras línguas é que grande parte dos surdos são filhos de pais ouvintes que recorrem a alternativas medicalizantes para superar a surdez, aproximandoos ao máximo da realidade ouvinte.

A luta, portanto, é para que haja um investimento linguístico cada vez maior. Para isso é preciso desenvolver um trabalho de conscientização frente ao ouvintismo e seus efeitos na sociedade para que não haja um retrocesso na filosofia atual de ensino, que é o Bilinguismo. E, neste ponto, tocamos mais uma vez no direito das crianças surdas de serem educadas em uma língua diferente da imposta à sociedade como a correta, um requisito para ser aceito, incluído.

\section{Metodologia}

Este estudo de caso foi realizado com o intuito de analisar os efeitos da pandemia de COVID-19 na educação de surdos no Município de Santo Antônio de Pádua, considerando os desafios que já existiam antes da medida do isolamento social e os que surgiram no decorrer deste tempo, devido às mudanças na logística das aulas, além de descrever tais mudanças, que continuam em um movimento de tentativas. Conforme Yin $(2009$, p. 1) "O estudo de caso é um método de pesquisa que utiliza, geralmente, dados qualitativos, coletados a partir de eventos reais, com o objetivo de explicar, explorar ou descrever fenômenos atuais inseridos em seu próprio contexto".

Com o método definido, delimitamos a unidade do caso, que compreende em conhecer a realidade do acesso ao ensino por parte dos(as) alunos(as) surdos(as) matriculados(as) na rede municipal de Santo Antônio de Pádua, que atualmente são 2 (dois), uma menina de 11 anos que está no $5^{\circ}$ ano e um menino de 9 anos que está no $4^{\circ}$ ano. A menina é fillha única, mora com seu pai e sua mãe na zona rural, já o menino, mora com os pais e seu irmão mais velho na cidade de Santo Antônio de Pádua desde o final de 2018, quando iniciou o aprendizado da Libras. Posteriormente, para a coleta de dados, utilizamos informações contidas em decretos publicados pela prefeitura relacionados à tomada de decisões e medidas orientadoras a serem respeitadas neste período, as obtidas através da participação de reuniões online dos profissionais da educação do município, mais especificadamente da escola de cada estudante surdo e do Núcleo de Apoio a Inclusão Educacional - NAIE, que é formado por um grupo de profissionais, 
dentre eles, psicólogo, assistente social, fonoaudiólogo e os professores do Atendimento Educacional Especializado - AEE, professor(a) de Braile e professores intérpretes de Libras. Esta reunião acontece com frequência e tem por intuito monitorar o que está sendo desenvolvido, o que pode ser melhorado e as dificuldades encontradas para que todos os alunos tenham acesso ao ensino com equidade. Além disso, informações de conversas constantes com as famílias dos discentes e seus respectivos intérpretes e docentes através do aplicativo whatsapp. Com os familiares da menina de 11 anos há a dificuldade da falta de internet e sinal de telefone, mas foi possível estabelecer contato aproveitando os momentos em que saiam de casa para um local com área e respondiam as mensagens enviadas ou ligavam. Por meio dos dados coletados, realizamos a interpretação e análise detalhada para, então, elaborarmos o texto. Para fundamentar o trabalho foi utilizado o pensamento de autores como Skliar, Larrosa, Quadros, Gil, Yin e Bakhtin.

\section{Considerações finais}

O movimento de inclusão da pessoa com surdez em escolas regulares, regidas por um idioma oficial, no caso a norma padrão culta do português, não contempla satisfatoriamente a educação de pessoas surdas, independente do ano escolar e modalidade de ensino (virtual ou presencial). O direito à educação deste estudante implica na contratação de um intérprete, mas isto não garante seu aprendizado. Infelizmente, a política educacional não contempla em seus currículos a diversidade linguística, afastamento que é ratificado na formação de professores de português, por cobrar uma percepção sonora que, em grande parte das vezes, nem o professor se dá conta por ser algo tão natural dos usuários da língua, que é oral-auditiva. No entanto, ter 1 (um) aluno surdo em 1 (uma) escola não tira seu direito de expressar-se utilizando sua língua natural, a Língua de Sinais, mas, devido às pressões ouvintistas, que o coloca contra a parede por ser o diferente, o problema, aquele que precisa se adaptar, acaba cedendo ao esforço de procurar formas de "medicalizar" a surdez.

A linguagem utilizada pelo surdo, seja através da língua ou da escrita, é alvo de preconceitos por não se enquadrar às "normas" e é necessário que os docentes compreendam como acontece o pensamento do surdo, que, por maior que seja seu vocabulário, sempre pode haver palavras que precisam ser contextualizadas, apresentadas de maneira visual, relacionadas a sinais ou a imagens que permitam ligações concretas. Relações que, quando nos dispomos a perceber, revelam-nos o quanto são ricas as formas de pensar das pessoas e o quanto precisam ser mostradas e discutidas. 
Todos esses desafios que envolvem a linguagem, tudo que se esbarra nela e gera atrito, somam-se aos efeitos da pandemia do COVID-19. No Município de Santo Antônio de Pádua percebemos que os aspectos linguísticos continuam em evidência, porém com novos desafios requeridos pela adesão do ensino virtual. A interação dos(as) alunos(as) surdos(as) com seus professores e colegas tornou-se ainda mais dificultada e distante devido à complicadores como a falta de acesso à internet, a ausência do campo visual ou fatores que interferem na utilização deste recurso. O contato visual é necessário para estabelecer uma comunicação mais adequada com os estudantes e, portanto, interfere no desempenho do trabalho do intérprete de Libras, profissional que muitas vezes é cobrado a realizar tarefas que não competem ao seu cargo ou à sua formação, mas, como foi exposto, deve se orientar e respeitar a legislação que regulamenta sua profissão, especialmente seu Código de Ética. Outro ponto de alerta mencionado foi a dificuldade da família em oferecer suporte ao aprendizado da criança. Fala-se muito sobre democracia neste período de isolamento, mas, será que a educação pré-pandemia era democrática? Aliás, a educação é um ato político, como nos ensinou Paulo Freire e, consequentemente, nossas ações precisam ser um ato de coragem perante relações de poder que permanecem diminuindo os seres humanos, selecionando-os e excluindo-os.

\section{Referências}

BAGNO, M. A língua de Eulália: novela sociolinguística. 15 ed. - São Paul: contexto, 2006.

BAKHTIN, M. Marxismo e Filosofia da Linguagem: Problemas Fundamentais do Método Sociológico na Ciência da linguagem. ed.1 ${ }^{\text {a }}$; tradução Sheila Grillo e Ekaterina Vólkova Américo. In: Educação em Tempos de Pandemia: Brincando com um Mundo Possível. LIBERALI, F. at al. São Paulo: Editora: 34, [1929] 2017.

BRASIL. Lei $n^{\circ} 12.319$, de $1^{\circ}$ de Setembro de 2010.Regulamenta a profissão de Tradutor e Intérprete da Lingua Brasileira de Sinais - LIBRAS. Brasília, 2010. Disponível em: http://www.planalto.gov.br/ccivil 03/ Ato2007-2010/2010/Lei/L12319.htm. Acesso em: Agosto de 2020.

BRASIL. Lei Brasileira de Inclusão da Pessoa com Deficiência, ${ }^{\circ} 13.146$ de 6 de julho de 2015. Brasília, 2015. Disponível em: http://www.planalto.gov.br/CCIVIL_03/Ato20152018/2015/Lei/L13146.htm. Acesso em: Agosto de 2020.

BRASIL. Decreto $N^{o}$ 5.626, de 22 de dezembro de 2005. Brasília, 2005. Disponível em: http://www.parfor.ufpa.br/legislacao/Decreto\%205626-2005\%20Libras.pdf. Acesso em: Agosto de 2020. 
DORDIAT, A.; ARAÚJO, J. R. de. O Intérprete de Língua de Sinais no Contexto da educação Inclusiva: O pronunciado e o executado. Rev. Bras. Ed. Esp., Marília, v. 18, n. 3, p. 391-410, Jul.-Set., 2012

GIL, A. C. Como elaborar projetos e pesquisa. 3a ed. São Paulo: Atlas; 1995:58. In: VENTURA, M. O Estudo de Caso como Modalidade de Pesquisa. Pedagogia Médica, Rio de Janeiro, 2007.

LARROSA, J. Literatura, experiência e formação. In: COSTA, M. (Org). Caminhos investigativos. Porto Alegre: Mediação, 1996.

PÁDUA, M. S. A. Decreto Municipal No 027/2020. Santo Antônio de Pádua, Rio de Janeiro, 2020. Disponível em:

https://docs.google.com/viewer?url=http://www.santoantoniodepadua.rj.gov.br/area restrita/ modulos/transparencia/arquivos/262c61DECRETO NA 02720 REGRAS DE COMBATE AO COVID19 1.doc. Acesso em: Agosto de 2020.

PÁDUA, M. S. A. Decreto Municipal $N^{o} 051 / 2020$. Santo Antônio de Pádua, Rio de Janeiro, 2020. Disponível em:

https://docs.google.com/viewer?url=http://www.santoantoniodepadua.rj.gov.br/area restrita/ modulos/transparencia/arquivos/74df2cDECRETO NA 05120 ANTECIPA_FARIAS ESC OLARES COVID19.doc. Acesso em: Agosto de 2020.

QUADROS, R. M. de. O tradutor e intérprete de língua brasileira de sinais e língua portuguesa. 2. ed. Secretaria de Educação especial. Brasília: MEC/SEESP, 2007.

SKLIAR, C. A surdez: um olhar sobre as diferenças. 8 ed., Porto Alegre: Mediação, 2016.

SKLIAR, C. A Inclusão que é "nossa" e a diferença que é do "outro". In: Inclusão e educação: Doze olhares sobre a Educação Inclusiva. / David Rodrigues (Org.). São Paulo: Summus, 2006.

YIN, R.K. Case study research, design and methods (applied social research methods). Thousand Oaks. In:BRANSKI, R.; CALDEIRA, R.; LIMA Jr, F. Metodologia de Estudo de casos aplicada à Logística.California: Sage Publications. 2009.

\footnotetext{
${ }^{\text {i } M e s t r a n d a ~ e m ~ E n s i n o ~ p e l a ~ U n i v e r s i d a d e ~ F e d e r a l ~ F l u m i n e n s e, ~ P e d a g o g a, ~ P r o f e s s o r a ~ I n t e ́ r p r e t e ~ d e ~ L i b r a s ~ n o ~}$ Município de Santo Antônio de Pádua. E-mail: jessikafigalves@hotmail.com Santo Antônio de Pádua, Brasil. Orcid: https://orcid.org/0000-0002-3898-8224

ii Professora Adjunta da Universidade Federal Fluminense e do PPGEn. Coordenadora do Observatório da Inclusão Educacional e Direitos Humanos. Doutora em Filosofia. E-mail: jsgomes@id.uff.br Niterói, Brasil. Orcid: https://orcid.org/0000-0002-8609-5893
} 